\title{
How Much Knowledge and Awareness of Faecal Incontinence Is There in Primary Care?
}

\author{
Michael Shinkwin ${ }^{1, *}$, Jade Brown ${ }^{2}$, Lily Scourfield ${ }^{2, *}$ (D) and Julie Cornish ${ }^{1, *}$ \\ 1 Colorectal Department, University Hospital of Wales, Cardiff CF14 4XW, UK \\ 2 School of Medicine, Cardiff University, Cardiff CF10 3AT, UK; jadeh118@hotmail.co.uk \\ * Correspondence: michael.shinkwin@wales.nhs.uk (M.S.); ScourfieldL@cardiff.ac.uk (L.S.); \\ julie.cornish@wales.nhs.uk (J.C.); Tel.: +44-292-0742-934 (J.C.)
}

Citation: Shinkwin, M.; Brown, J.; Scourfield, L.; Cornish, J. How Much Knowledge and Awareness of Faecal Incontinence Is There in Primary Care? Surgeries 2021, 2, 150-156. https://doi.org/10.3390/ surgeries2020015

Academic Editor: George

Theodoropoulos

Received: 18 January 2021

Accepted: 8 April 2021

Published: 14 April 2021

Publisher's Note: MDPI stays neutral with regard to jurisdictional claims in published maps and institutional affiliations.

Copyright: (C) 2021 by the authors Licensee MDPI, Basel, Switzerland. This article is an open access article distributed under the terms and conditions of the Creative Commons Attribution (CC BY) license (https:/ / creativecommons.org/licenses/by/ $4.0 /)$.

\begin{abstract}
Faecal incontinence (FI) is a debilitating symptom with a likely underreported incidence in the general population. Postpartum or postmenopausal women are at increased risk of this. General Practitioners (GPs) have a vital role in screening patient groups with FI. Knowledge of the underlying diseases associated with FI is important for all clinicians who have contact with this patient group. An online questionnaire (Survey Monkey ${ }^{\mathrm{TM}}$, San Mateo, CA, USA) was sent to GPs in Wales and England through a deanery, social media and GP educational groups. Questions: A total of 250 participants completed the questionnaire-195 GPs and 55 GPSTs. Two-thirds had no coloproctology experience, but $70 \%$ had worked in obstetrics and gynaecology. In total, 70\% had no formal FI training and $75 \%$ felt insufficiently informed about FI. A total of $80 \%$ felt that GPs need specific training on FI. A third of respondents used the 6-week postnatal check to assess maternal bowel function and most did not appreciate faecal urgency as a symptom. Patients should be asked about FI symptoms by GPs, particularly those populations at increased risk. Our GP survey participants were enthusiastic for more education on the treatment options and where to signpost patients with FI.
\end{abstract}

Keywords: faecal incontinence; anal incontinence; primary care; sphincter injury; postpartum

\section{Introduction}

Faecal incontinence (FI) is defined as the involuntary loss of faeces, be it liquid or solid, and is a symptom rather than a diagnosis [1]. Anal incontinence (AI) involves the additional loss of control passing flatus [1]. The incidence is reported as between 2 and $10 \%$ in the general population [2], but the incidence and prevalence are felt to be generally underestimated. Patients can feel unable to voluntarily disclose that they are suffering from FI due to the stigmatising nature of the condition, and previous data show over $70 \%$ of patients failing to discuss this with their doctor [3]. Those who do disclose this to their general practitioner (GP) are more likely to be experiencing severe FI which they are no longer able to cope with alone [3]. This is discouraging as there is treatment available and conservative management alone can improve symptoms in $60 \%$ of cases and restore continence in $20 \%$ of patients [3].

Although FI is not life threatening, it is still important because of the significant detrimental impact on the patients' quality of life [4]. Recognition requires education and understanding of a subject [5]. A 2010 survey of medical, nursing and allied health professional undergraduate curriculums illustrated inadequate teaching about urinary and faecal continence problems [6]. An updated survey conducted by a member of our institution has shown faecal incontinence still does not feature in the undergraduate curriculums of the medical Royal Colleges (Royal College of General Practitioners, Royal College of Surgeons England, BGS, RCPCH) [7].

Our aim with this questionnaire was to look at base levels of understanding of FI in the GP and GPST population. The secondary aims were to assess how these clinicians want to learn, which will influence the design of education material for local trainees. 


\section{Materials and Methods}

\subsection{Study Design}

This was a cross-sectional study using questionnaires on UK GPs and Welsh GP trainees which was delivered via online Survey Monkey ${ }^{\mathrm{TM}}$. The questionnaire was distributed to GPSTs via the Postgraduate Welsh Deanery Email. The link to the survey was also advertised on specific GP interest Twitter/Facebook accounts and other social media platforms. The surveys were completed between October and November 2018.

\subsection{Survey Instrument}

The 27-question anonymous online survey assessed general practitioners' awareness and knowledge of the presenting symptoms of faecal incontinence. The final questionnaire was divided into three main sections: (i) demographics plus previous specialty experience, (ii) clinical knowledge of faecal incontinence presentation and (iii) preferences for information gathering and learning. The questions were developed with input from the multidisciplinary team who are involved with the pelvic floor service at University Hospital of Wales. The questionnaire was initially piloted at a local GP education day on 24 participants. The feedback from the pilot was used to develop the final version which was sent out. All questions were multiple choice with a select few allowing for free-text responses.

\section{Results}

A total of 250 participants completed the questionnaire-195 GPs and 55 GPSTs. This gives us a response rate for 11\% GPST. The denominator for GPs is unknown due to the method of distribution. The majority of qualified GPs were aged 31-40 (55\%), 25\% were aged $41-50$ and $12 \%$ were over 50 years old. The trainee cohort had a younger age distribution of participants, with the majority under the age of 30; overall, however, the largest age category was 31-40 with 52\%. There was a female predominance in both the GP and GPST groups of 85 and 75\%, respectively.

Both groups had similarly low levels of colorectal placement during the initial part of their careers (Table 1). In total, 7\% of GPs rotated through an obstetrics and gynaecology placement and $51 \%$ of GPSTs (Table 1 ).

Table 1. Demographics.

\begin{tabular}{|c|c|c|c|}
\hline \multicolumn{4}{|c|}{ Gender } \\
\hline & GP $(n=195)$ & GPST $(n=55)$ & Combined $(n=250)$ \\
\hline Female & $88 \%$ & $75 \%$ & $85 \%$ \\
\hline Male & $12 \%$ & $25 \%$ & $15 \%$ \\
\hline \multicolumn{4}{|c|}{ AGE } \\
\hline & $\mathrm{GP}(n=55)$ & GPST $(n=195)$ & Combined $(n=250)$ \\
\hline $20-30$ & $7.7 \%$ & $52.7 \%$ & $17.6 \%$ \\
\hline $31-40$ & $55.4 \%$ & $40.0 \%$ & $52.0 \%$ \\
\hline $41-50$ & $25.1 \%$ & $1.8 \%$ & $20.0 \%$ \\
\hline $50>$ & $11.8 \%$ & $5.5 \%$ & $10.4 \%$ \\
\hline \multicolumn{4}{|c|}{ Colorectal Post as Part of Training $(n=250)$} \\
\hline GP & & & No $62 \%$ \\
\hline GPST & & & No $76 \%$ \\
\hline \multicolumn{4}{|c|}{ Obstetrics and Gynaecology Post as Part of Your Training $(n=250)$} \\
\hline GP & & & No $23.6 \%$ \\
\hline GPST & & & No $49.1 \%$ \\
\hline
\end{tabular}

Only $24 \%(n=60)$ of those surveyed had received information on faecal incontinence and $50 \%$ of the responders said they had sought out information about faecal incontinence (Table 2). In total, $80 \%$ of GPs were interested in additional information about faecal incontinence and $80 \%$ did feel GP/GPSTs should get some specific training on the subject (Table 2). 
Table 2. Faecal incontinence education.

During You GP Training, Have You: (Combined Results) $(n=250)$

-Ever received information on FI?

-Ever searched for information on FI?

-Do you feel sufficiently informed about FI?

-Are you interested in more infor-mation on FI?

-Do you think this is something GPs should be given specific training on?

Have You Been on Any Specific Pelvic Floor Courses $(n=250)$

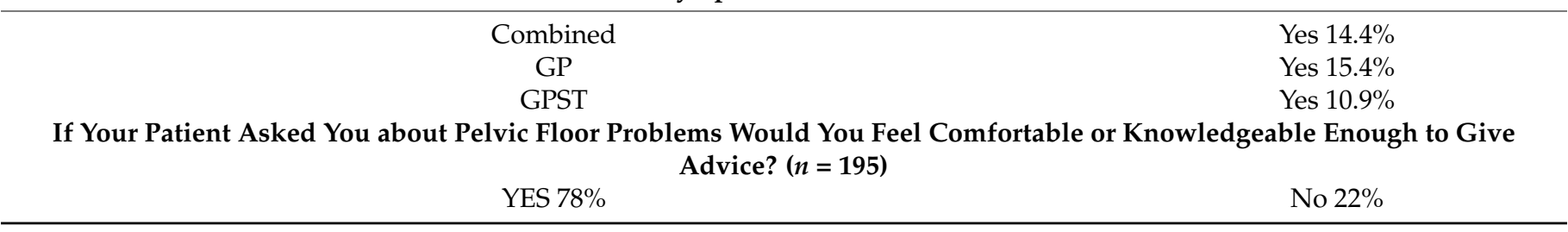

Over $80 \%$ of responders were aware of local continence teams in their local hospital (Table 3). A total of $44 \%$ of responders would initially refer to colorectal surgical clinic followed by a primary care continence team (Table 3). The responders largely recognised the need for referral in instances of occasional leakage of faeces. Faecal urgency was unfortunately not deemed a priority by $60 \%$ of the cohort (Table 3 ).

Table 3. Faecal incontinence management.

\begin{tabular}{|c|c|c|}
\hline \multicolumn{3}{|c|}{ Are you Aware of Any Continence Services in Your Local Health Board? } \\
\hline Combined $(n=226)$ & \multicolumn{2}{|c|}{ Yes $84.1 \%$} \\
\hline $\mathrm{GP}(n=177)$ & \multicolumn{2}{|c|}{ Yes $87.6 \%$} \\
\hline GPST $(n=49)$ & \multicolumn{2}{|c|}{ Yes $71.4 \%$} \\
\hline \multicolumn{3}{|c|}{ If You Had a Patient with FI Where Would You Initially Refer the Patients to? (Please Tick All Relevant) } \\
\hline & $\mathrm{GP}(n=177)$ & GPST $(n=49)$ \\
\hline Primary Care Continence Team & $35.0 \%$ & $36.7 \%$ \\
\hline Pelvic Floor Nurses (in Hospital) & $13.6 \%$ & $18.4 \%$ \\
\hline Physiotherapy & $17.5 \%$ & $24.5 \%$ \\
\hline Colorectal Surgeons & $43.5 \%$ & $46.9 \%$ \\
\hline Obstetric Team & $7.9 \%$ & $20.4 \%$ \\
\hline Other (please specify) & $0.0 \%$ & $10.2 \%$ \\
\hline \multicolumn{3}{|c|}{ Which Patient Symptoms Require Physiotherapy Referral? } \\
\hline & GP $(n=177)$ & GPST $(n=49)$ \\
\hline $\mathrm{C} / \mathrm{o}$ occasional leakage of faeces & $70.45 \%$ & $57.1 \%$ \\
\hline Inability to control flatus & $63.28 \%$ & $44.9 \%$ \\
\hline Precautionary use of a pad for soiling & $58.19 \%$ & $55.1 \%$ \\
\hline $\mathrm{C} / \mathrm{o}$ faecal urgency & $40.68 \%$ & $36.7 \%$ \\
\hline \multicolumn{3}{|c|}{ Which Patient Symptoms Require Referral to Continence Team? } \\
\hline & $\mathrm{GP}(n=177)$ & GPST $(n=49)$ \\
\hline C/o occasional leakage of faeces & $78.9 \%$ & $81.6 \%$ \\
\hline Inability to control flatus & $40.0 \%$ & $46.9 \%$ \\
\hline Precautionary use of a pad for soiling & $66.3 \%$ & $71.4 \%$ \\
\hline $\mathrm{C} / \mathrm{o}$ faecal urgency & $43.8 \%$ & $44.9 \%$ \\
\hline \multicolumn{3}{|c|}{ Does Age Play A Role in Your Referral to Continence Team? } \\
\hline Combined $(n=226)$ & & \\
\hline $\mathrm{GP}(n=177)$ & & \\
\hline GPST $(n=49)$ & & \\
\hline \multicolumn{3}{|c|}{ Do You Ever Refer Men to the Continence Team? } \\
\hline Combined $(n=226)$ & & \\
\hline $\mathrm{GP}(n=177)$ & & \\
\hline GPST $(n=49)$ & & \\
\hline
\end{tabular}


General practitioners responding in the survey use a wide range of resources when researching a topic. The most common source of information for both cohorts was GP notebook (website), guidelines, colleagues and BMJ Learning. GP Notebook and guidelines were the most preferred resource for both GPSTs and GPs alike (Figure 1), but GPSTs had a preference for guidelines and GPs had a marginal preference for GP (Figure 2) Notebook. In total, $95 \%$ of the cohort was aware of what a podcast was, and just over half of all responders listened to any type of podcast. A total of $75 \%$ of the responders expressed an interest in using a podcast as a delivery format for surgical teaching. Additionally, $63 \%$ of those surveyed already use BMJ Learning for their continuing education but nearly $90 \%$ said they would be interested in a faecal incontinence BMJ Learning module.

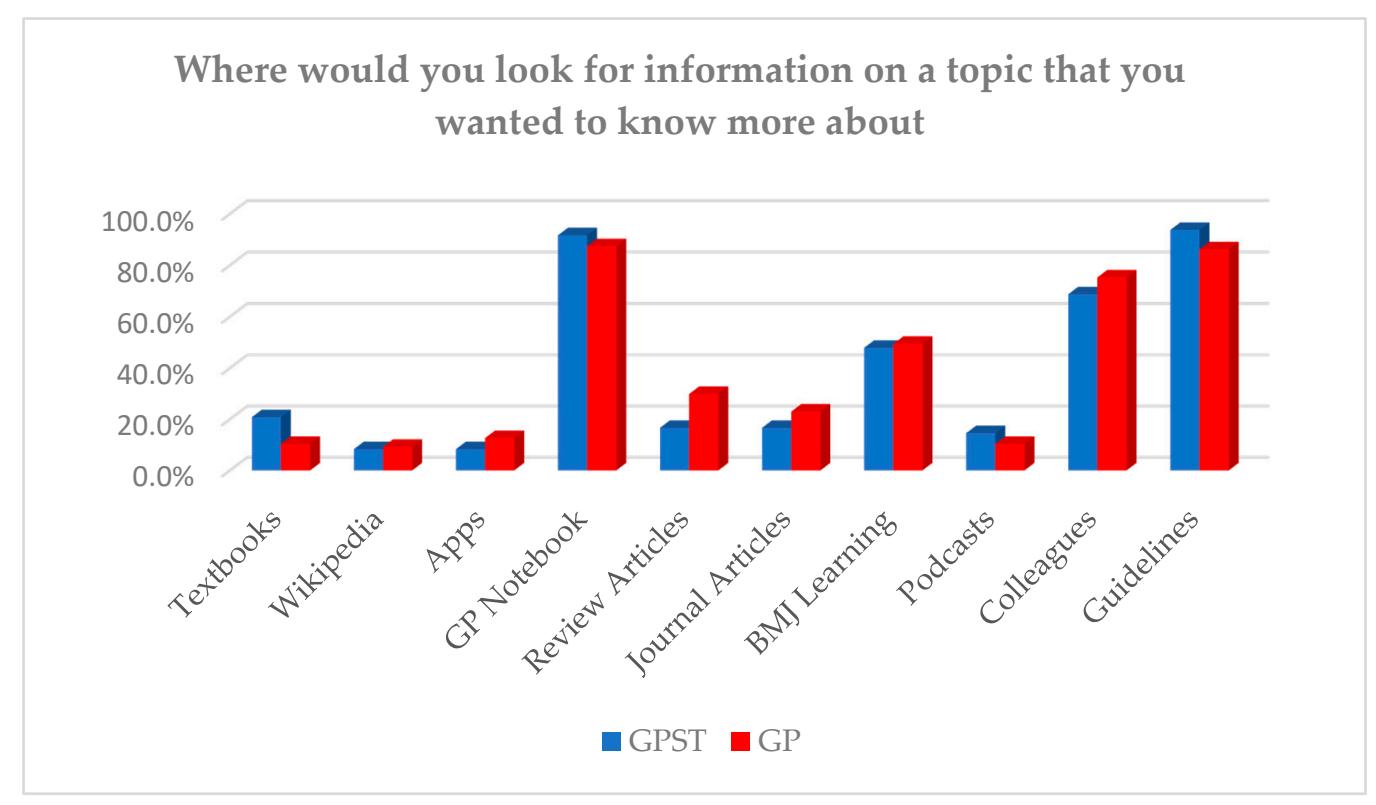

Figure 1. What resources do General Practitioner (GP) and GPSTs use for educational purposes (able to select multiple).

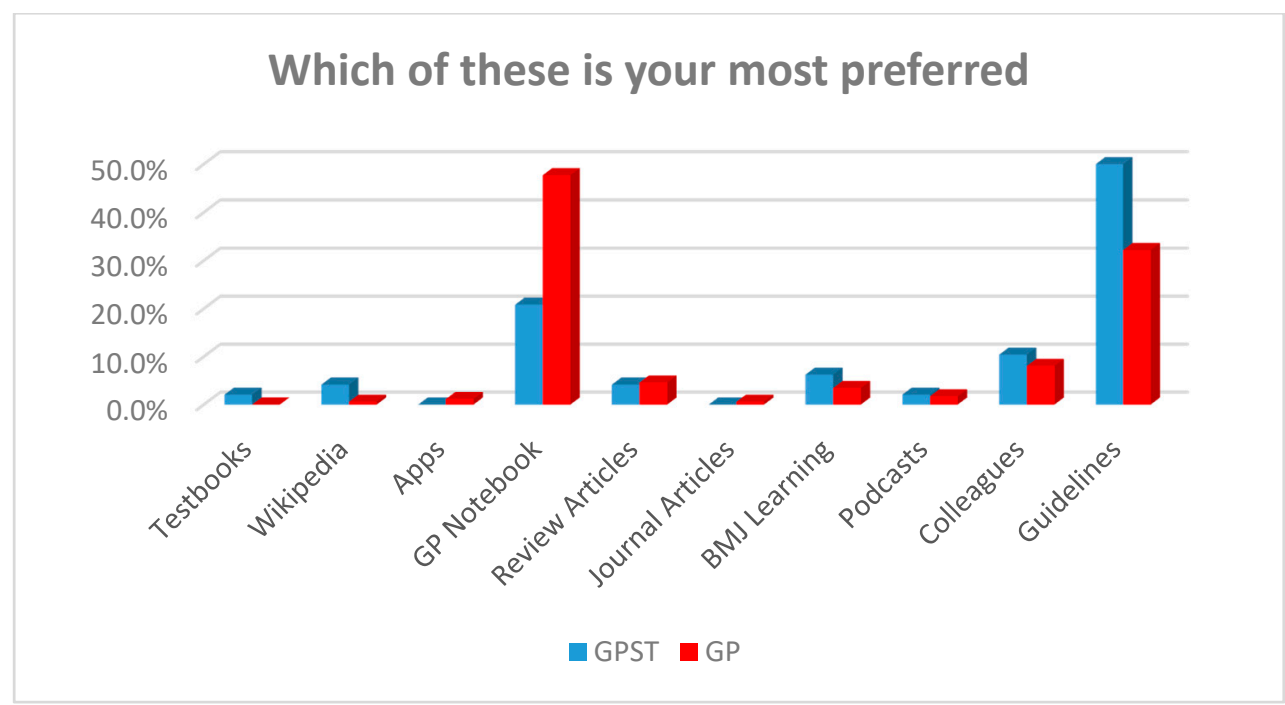

Figure 2. What resources do GP and GPSTs prefer to use for educational purposes (only able to select one)?

\section{Discussion}

The results of this cross-sectional study suggest there is awareness of FI amongst GPs and GP trainees, but it is not universal and there is an appetite amongst primary care clinicians to be better informed about FI through a variety of teaching materials. 
This study suggests there is a deficiency in education of general practitioners about faecal incontinence, but there is enthusiasm to change this. Work conducted over a decade ago by Thekkinkattil and colleagues in 2007 also showed limited knowledge in primary care [8]. Several National Audits of Continence (2006, 2008, and 2010) have highlighted that inadequate professional education is a factor which has contributed to poor continence care of patients in primary and secondary care. In Spain the GIFT Project undertook an education program with general practitioners, practice nurses and community based midwifes [9]. The detection of faecal incontinence consequentially increased from less than $1 \%$ preintervention to $4.8 \%$.

The GPST syllabus has to cover a wide range of topics and GPs are not expected to have a specialist understanding of faecal incontinence. Faecal incontinence only has one reference in the GPST syllabus-urinary incontinence has eight [10]. The limited inclusion of FI content in the syllabus may be one cause of the lack of information/knowledge in GPs. By using responses from the final part of our survey, particularly the local trainees, we can determine the direction for the formation of education resources. The surveyed cohort expressed an interest in utilising E-learning (BMJ Learning) to help improve their knowledge of FI. At present, there is no FI BMJ Learning. A survey or German GP trainees has shown a further positive change in attitude to E-learning over the last year due to the COVID-19 pandemic [11]. E-learning resources are currently being developed locally to assist with postgraduate education on FI in Wales.

Postpartum women are most at risk of FI in the initial 3 months, meaning the routine postnatal check-up is a perfect screening time woman for FI [12]. The role of the 6-8 week postnatal check-up has been discussed in the media and is part of Hidden Half Campaign by the National Childbirth Trust [13]. The current research shows that this time is largely focused on the baby and maternal health is not given much attention [14]. Our survey illustrates this problem with less than half of GPs surveyed taking this opportunity to ask screening questions for FI (Table 4). An update in the GP contract for 2020/21 with funding for a separate maternal appointment is proposed [15]. Screening questions are utilised in the antenatal period to help identify women at risk of domestic violence [16]. A bundle of questions at a formal postnatal check would increase detection of FI based on previous research.

Table 4. Recognition of symptoms.

\begin{tabular}{cc}
\hline Is Pelvic Pain after Delivery Normal? & Combined $(n=\mathbf{2 2 5})$-Yes \\
\hline Immediately postpartum? & $91.1 \%$ \\
1 month postpartum? & $29.3 \%$ \\
6 months postpartum? & $2.2 \%$ \\
Is Urinary Incontinence after Delivery Normal? & Combined $(n=\mathbf{2 2 6})$-Yes \\
\hline Immediately postpartum? & $59.6 \%$ \\
1 month postpartum? & $23.6 \%$ \\
6 months postpartum? & $4.4 \%$ \\
Is Faecal Incontinence after Delivery Normal? & Combined $(n=226)-$ Yes \\
\hline Immediately postpartum? & $16.8 \%$ \\
1 month postpartum? & $1.8 \%$ \\
6 months postpartum? & $0.4 \%$ \\
Is Dyspareunia after Delivery Normal? & Combined $(n=\mathbf{2 5})-$ Yes \\
\hline 1 month postpartum? & $63.6 \%$ \\
6 months postpartum? & $3.1 \%$ \\
Do You Ask Women about Symptoms of Faecal & \\
Incontinence as Part of the 6 Week Check or in the & Combined $(n=\mathbf{2 2 6})-$ Yes \\
Postpartum Period? & \\
\hline Yes & $41.2 \%$ \\
\hline & $58.8 \%$ \\
\hline
\end{tabular}


There are opportunities in general practice for bundles of questions to be used in the other high-risk populations such as nursing homes and patients of increased age. Patients aged 40-75 years old who are not already undergoing follow-up for chronic disease are offered interval health checks. While there is a lot to cover in these consultations, a question on FI to prompt a further review would again help with detection. Nursing homes in the UK are normally covered by a single GP practice. Screening of these patients could be carried out in conjunction with routine pharmacy reviews the GPs already undertake.

The limitation of this study is the difficulty in calculating the response rate. The methods used for distribution mean we do not know how many saw the link to the survey. In the GPST group there where 480 trainees at the time, giving an $11 \%$ response rate. Bias may have been introduced into the results with the GP group as those responding to the survey were members of women's health focused social media groups. The questionnaire was not set up to force all questions to be answer which has led to some inconsistencies in the number of responses per question.

\section{Conclusions}

Our study shows that there is need for improvement in GP's knowledge of faecal incontinence through various teaching avenues and that eLearning and podcast material could be developed in conjunction with the ROCG to improve this.

Author Contributions: Conceptualization, J.C.; methodology, J.C., J.B., L.S. and M.S.; investigation, J.C., J.B., L.S. and M.S.; data curation, M.S.; writing-original draft preparation, M.S. and J.B.; writing-review and editing, J.C. and M.S.; supervision, J.C. All authors have read and agreed to the published version of the manuscript.

Funding: This research received no external funding.

Institutional Review Board Statement: Not applicable.

Informed Consent Statement: Not applicable.

Data Availability Statement: The data presented in this study are available within the article.

Conflicts of Interest: The authors declare no conflict of interest.

\section{References}

1. Sultan, A.H.; Monga, A.; Lee, J.; Emmanuel, A.; Norton, C.; Santoro, G.; Hull, T.; Berghmans, B.; Brody, S.; Haylen, B.T. An International Urogynecological Association (IUGA)/International Continence Society (ICS) joint report on the terminology for female anorectal dysfunction. Int. Urogynecol. J. 2016, 28, 5-31. [CrossRef] [PubMed]

2. Sharma, A.; Yuan, L.; Marshall, R.J.; Merrie, A.E.H.; Bissett, I.P. Systematic review of the prevalence of faecal incontinence. Br. J. Surg. 2016, 103, 1589-1597. [CrossRef] [PubMed]

3. Whitehead, W.E.; Palsson, O.S.; Simrén, M. Treating Fecal Incontinence: An Unmet Need in Primary Care Medicine. North. Carol. Med. J. 2016, 77, 211-215. [CrossRef] [PubMed]

4. Meyer, I.E.; Richter, H. Impact of Fecal Incontinence and Its Treatment on Quality of Life in Women. Women's Health 2015, 11, 225-238. [CrossRef] [PubMed]

5. Callaghan, K.S.N. Factors influencing diagnostic decision-making. J. Prim. Health Care 2012, 4, 223-230. [CrossRef] [PubMed]

6. McClurg, D.; Cheater, F.; Eustice, S.; Burke, J.; Jamieson, K.; Hagen, S. A multi-professional UK wide survey of undergraduate continence education. Neurourol. Urodyn. 2012, 32, 224-229. [CrossRef] [PubMed]

7. Li, C.; Parker, J.; Reeves, N.; Cornish, J. Improving Medical Student's Knowledge and Understanding of Fecal Incontinence. Surgeries 2020, 1, 21-29. [CrossRef]

8. Thekkinkattil, D.K.; Sagar, P.M.; Lim, M.; Finan, P.J.; Burke, D. Awareness of investigations and treatment of faecal incontinence among the general practitioners: A postal questionnaire survey. Colorectal Dis. 2008, 10, 263-267. [CrossRef] [PubMed]

9. Ribas, Y.; Coll, M.; Espina, A.; Jiménez, C.; Chicote, M.; Torné, M.; Modolell, I. Initiative to improve detection of faecal incontinence in primary care: The GIFT Project. Fam. Pract. 2017, 34, 175-179. [CrossRef] [PubMed]

10. The Royal College of General Practioners. The RCGP Curriculum the Curriculum Topic Guides; The Royal College of General Practioners: London, UK, 2019.

11. Förster, C.; Eismann-Schweimler, J.; Stengel, S.; Bischoff, M.; Fuchs, M.; Von Luckner, A.G.; Ledig, T.; Barzel, A.; Maun, A.; Joos, S.; et al. Opportunities and challenges of e-learning in vocational training in General Practice-a project report about implementing digital formats in the KWBW-Verbundweiterbildungplus. GMS J. Med. Educ. 2020, 37, Doc97. [CrossRef] [PubMed] 
12. Gartland, D.; MacArthur, C.; Woolhouse, H.; McDonald, E.; Brown, S.J. Frequency, severity and risk factors for urinary and faecal incontinence at 4 years postpartum: A prospective cohort. BJOG Int. J. Obstet. Gynaecol. 2016, 123, 1203-1211. [CrossRef] [PubMed]

13. The National Childbirth Trust. Hidden Half Campaign: NCT. Available online: www.nct.org.uk/get-involved/campaigns/ hidden-half-campaign (accessed on 5 January 2020).

14. Lees, C.; Bartmann, D. The Physical and Mental Health of New Mothers often Receives Little or No Discussion at GP Check-Ups, New Polling Reveals. Available online: https://www.survation.com/the-physical-and-mental-health-of-new-mothers-oftenreceives-little-or-no-discussion-at-gp-check-ups-new-polling-reveals/Survation (accessed on 1 February 2020).

15. Primary Care Strategy and NHS Contracts Group. Update to the GP Contract Agreement 2020/21-2023/24 BMA; NHS England Leeds: Leeds, UK, 2020.

16. Lynch, L.; Hardacre, S. Hidden Tear-Listening Ears, An All Wales Approach to Antenatal Routine Enquiry into Domestic Abuse. All Wales Midwifery and Health Visitors Networking Group with Financial Assistance from the Welsh Assembly Government. March 2006. Available online: http:/ / www.wales.nhs.uk/sites3/documents / 699/Antenatal\%20Routine\%20Enquiry\%20Into\%20 Domestic\%20Abuse\%20-\%20Introduction.pdf (accessed on 18 January 2021). 